\title{
HOMO'POLY: UNDERSTANDING AND ACCEPTANCE OF DIVERSITY
}

\author{
Oliver Holz ${ }^{1}$, \& Lotte Geunis ${ }^{2}$ \\ ${ }^{1}$ Faculty of Economics and Business, University of Leuven (Belgium) \\ ${ }^{2}$ Maastricht Graduate School of Governance, Maastricht University (The Netherlands)
}

\begin{abstract}
Sustained gender-specific inequalities in education and upbringing continue to be exposed in numerous studies and surveys. In response to this persistent challenge, national and international organizations are looking to strengthen their co-educational infrastructure to better accommodate the specific needs of all pupils and students, regardless of their sexual orientation, with a view to fighting discrimination and promoting tolerance towards diversity.

The 2015 European Union Lesbian, Gay, Bisexual and Transgender survey illustrated the urgency of the issue. Considerable challenges present themselves at different levels: nationwide controversy about the incorporation of the topic of homosexuality into school curricula, controversial discussions about the implementation of gay marriage, homophobic attacks and bullying (particularly at a young age), the outing of and dealing with homosexual migrants, homophobic behaviour in sport, and homophobic legislation that restricts or even rolls back the rights and protections of the Lesbian, Gay and Bisexual (LGB) community.

This article introduces 'Homo'poly', a European project on homosexuality in schools that was launched in 2016 to address these issues. The aim of this strategic partnership (KA2 ERASMUS+) is to contribute towards a better understanding of homosexuality in secondary and tertiary education.
\end{abstract}

Keywords: Gender, homosexuality, migration, diversity, didactical material.

\section{Introduction of the project}

Homo'poly has adopted a cross-sectoral approach in cooperation with eight countries, with one university and one secondary school participating from each country. This strategic partnership is a KA2 ERASMUS+ project, funded by the European Union, which targets students and lectures in university colleges and universities, as well as students and teachers in secondary education. The countries in which Homo'poly is active are Belgium, Germany, Hungary, Poland, the Netherlands, Spain, Turkey and the United Kingdom. Homo'poly was officially launched in September 2016 and will end in August 2019.

\section{Objectives}

Homo'poly's overall objective is to promote a better understanding and acceptance of diversity, specifically the LGB community in schools.

Because sustained gender-specific inequalities in education and upbringing persist, national and international organizations are looking to strengthen their co-educational infrastructure to better accommodate the specific needs of all pupils and students, regardless of their sexual orientation, with a view to fighting discrimination and promoting tolerance towards diversity.

The relevance and challenges of these issues remain evident on different levels: nationwide controversy about the incorporation of the topic of homosexuality into school curricula, the controversial discussion about the implementation of gay marriage, homophobic attacks and bullying (particularly at a young age), the outing of and dealing with homosexual migrants, homophobic behavior in sport, homophobic legislation of LGBTI-people in Russia and likewise many African countries, with images published and distributed by the mass media helping fuel it further. 
Homo'poly set out to make a contribution towards better understanding and broader acceptance of homosexuality in schools, both in tertiary and secondary education. The project therefore targeted students and lecturers at teaching colleges and universities, teachers in secondary education and students at secondary schools. To achieve this, three objectives were set.

\subsection{Objective 1: country-specific and comparative analysis}

Homo'poly set out to deliver a comprehensive assessment and a comparative study on the mission, aims and content of gender-appropriate behaviours in educational institutions (for example: the topic of homosexuality in the training of teachers, in curricula and teaching resources for secondary schools) and of complementing non-school initiatives in other educational institutions.

\subsection{Objective 2}

Homo'poly committed to developing a toolkit for teacher trainees and teachers consisting of two curriculum modules. The first one, 'Gender \& Homosexuality', covering general diversity of lifestyles, sexual identities, the question of coming-out and sexual well-being, was to be established across target groups and will form the basis of a school project over a period of several days. The second one, curriculum module 'Migration \& Homosexuality', was to take into account the problematic situation of refugees in Europe. Implementation and evaluation of these modules was scheduled to take place in all participating secondary schools in the third year of the project. Each module counts as 3 ECTS.

\subsection{Objective 3}

Homo'poly set out to work with the teachers of its secondary schools to develop 12 didactical materials related to the modules and issues mentioned above. These materials would also be tested and implemented in these schools during the third year of the project. By working closely with teachers and their students throughout this process, the project envisioned effective and sustainable integration of these materials in the school curriculum.

It should further be noted that Homo'poly also developed a Knowledge Portal, available at www.homopoly.eu. The resources, modules and materials developed in the context of the project were published as they became available and will remain at the disposal of the general public in the future.

\section{Results}

\subsection{Result 1}

The country-specific and comparative study were published in the 2018 Somewhere Over the Rainbow: Discussions on Homosexuality in Education Across Europe publication. The research carried out by the project partners confirmed that the eight countries involved have strongly diverging track records where homosexuality is concerned. Where the Netherlands are widely considered a pioneer on gay rights, Hungary faces a rapidly shrinking civic space for gays and bisexuals. Religious convictions render homosexuality a difficult topic in Turkey, Poland and - to a lesser extent - Spain, whereas the UK is keen to portray itself as progressive but lags behind in practice. Belgium appears reasonably comfortable embracing homosexuality, but here too, equal rights, protections and opportunities still too often elude the LGB community.

The studies consider these trends in greater detail and shed some light as to how and why homosexuality is (or is no longer) such a divisive issue across Europe. To frame the context, the publication explores the attitudes towards homosexuality of teachers, pupils and parents in Homo'poly's eight participating countries. Reviewing a unique range of survey results - from over 6,000 pupils, teachers and parents - the comparative study sets out to capture how young people see homosexuality, and what role schools (can) play in shaping these views. The study outlines the data collection methodology and presents the results and key findings. As this is the first qualitative analysis on homosexuality in these eight countries, these results provide new insights that can help guide policy recommendations in this area.

\subsection{Result 2}

The two modules - on homosexuality and migration, respectively - were published in 2019 . Each module offers text-based introductions as well as discussion questions, stories and additional resources.

Module 1, on gender and homosexuality, celebrates the project's commitment to equality and diversity. It consists of four sections: 1) sexual identities; 2) coming out; 3) sexual health and 4) different ways of living. The key aim for this module is to provide an understanding of different constructions of gender and homosexuality over the last 50 years. Teachers and teacher trainees are encouraged to 
examine cultural, social and political perspectives, constructions and conceptions of gender and homosexuality and apply this understanding to the challenges facing young people in schools and in their family and societal contexts. The module also offers you a broad understanding of different ways of conceptualising gender and sexuality and issues affecting LGBT communities in different global contexts.

The second module tackles homosexuality and migration. Around the world more than 70 countries consider homosexuality illegal, in five of these the death penalty can apply. The persecution and discrimination many LGB people face, can be enacted by state officials, but is also often experienced within their own communities and families without any recourse to protection. This module also consists of four sections: 1) leaving and arriving, 2) LGB with a migration background, 3) roles and fears and 4) supporting and consultancy institutions. Together they explore how migration affects the experiences of LGB pupils, including, but not exclusively, those from immigrant backgrounds. The key aim for this module is to have teachers and teacher trainees consider the challenges faced in increasingly diverse classrooms and how teachers can learn to create safe spaces for all pupils in an inclusive, collaborative classroom setting analysing the benefit that resources, professional agencies and legal support can offer.

\subsection{Result 3}

Twelve didactical materials were developed by the secondary school partners of the Project, ranging from games to discussion and debate instructions to booklets, stories and more creative activities such as story-telling and sketching. Most materials were developed for classroom use only, but some also include the involvement of parents and others. All materials are available on the Homo'poly website. During the third year of the project, every school set out to test these materials. Three of them were tested by every school (the game of life, the debate and the colorful families); each school was then free to choose a additional one to three further materials to test.

Overall feedback was excellent: while some materials did require further tweaking, they were generally very well received and had a measurable and noted impact on the teachers and pupils involved. Germany's coordinators indicated that "pupils had a lot of fun, but also felt very proud to participate in the project. The two days of testing were very intense, but they proved that the produced materials are very well-suited to approach different aspects of homosexuality in school, all in a way that, on the one hand, enriches the students' knowledge about the topic, and, on the other hand, invites them to change perspective, exchange opinions and arguments."

Feedback from the United Kingdom was similarly positive, with the Deputy Head of the Eaton Trust Academy sharing the following note with the Homo'poly team: "I visited all of the year 8 groups during lesson 1 this morning and wanted to give you some feedback. Every group was fully engaged and I saw absolutely no immature behaviour, embarrassment or silliness. Students offered sensible answers and listened carefully to each other. They were curious about some of the terminology and discussed their ideas carefully. Many students were very articulate and were able to extend their verbal responses with confidence. In one group a student said that they would not have thought about some of the issues had it not been for the lesson. There was a lot of genuine interest in the activities. The resources were clearly understood and the pace was maintained. The style and speed with which teachers were getting through the activities varied which evidenced the ability to differentiate the tasks according to the ability and understanding of the group. I have since spoken to a number of the teachers involved who really enjoyed delivering what could have been difficult material."

Last but not least, feedback from Poland, arguably the most difficult country context, was highly encouraging: "I tested these topics in 10 classes (150 people), lesson scenarios with students aged (13-14) and (15-16 years). My observations oscillate around issues related to substantive preparation for classes, and thus to the subject. Some of them turned out to be very well prepared in terms of content, which could be felt during the Oxford debate. Also during the division of students into three class teams, one could feel professionalism. The students were involved in the implementation of the project, which aimed to reduce the scale of hatred / dislike towards LGBT people. Only a few students could not find themselves during the lesson, they were embarrassed or reluctant to talk. The classes were accompanied by culture of speech and understanding. Students felt that they had a mission to fulfill, that their behavior in the game depends a lot. They were saying: it's great, we have never talked so sincerely about each other, for example, we did not know a lot about these issues. The students were very interested and open".

In recognition of the work done, the German "Schule der Vielfalt" network award will be offered to each secondary school during Homo'poly's end conference. 


\section{Lessons learned}

As the project is coming to a close, project partners are carefully considering lessons learned and take-aways for future work in this area. Three provisional lessons are shared below, for reflection and to encourage further (academic) engagement on these issues.

\subsection{Going against the grain: homophobia in Eastern Europe and Turkey}

The comprehensive geographical reach of Homo'poly was considered a major strength of the project, but it was always clear that this would also come with certain challenges. Cultural differences in the 'West' are manifest in gender-specific education and upbringing, in gender-specific interactions and attitudes towards tolerance, diversity, and homosexuality. But unsurprisingly, it is in the participating countries from Central and Eastern Europe and Turkey that Homo'poly experienced some notable challenges.

In Poland, Under the persistent influence of the Catholic Church, educational institutions are now being directed to remove all references to sexual diversity or LGBT+ from the national curricula. On top of this, strong political pressure along the same lines means that it is nearly impossible for school administrations to protect their LGB students and staff. This made it difficult for our participating schools and teachers to develop and test the project materials - and it is to their great credit that such quality results were achieved in such a difficult context. Note the final piece of feedback from the testing phase in Poland: "Information about my lessons has spread through the word of mouth. In another school where I teach (for 4 months), the pupils themselves suggested that I should teach them a lesson that they have already heard about from their peers from another school- SP11 - my mother's institution. I was surprised that students from other schools communicate to each other what is happening in their classes. It was a very positive and pleasant experience."

In Hungary, results were similarly positive - due in large part to the concerted efforts of the partners, who had been involved in similar projects before and had strong personal commitments to these issues. While Homo'poly is proud of the results it has delivered, it remains regrettable that these are due the result of individual efforts, not of systematic or structural changes towards a more positive view or acceptance of LGB - this remains a long way off.

In Turkey, collaboration with the tertiary institution was equally smooth, but no secondary school was willing to participate. Throughout the course of project, the political context became more difficult. Project partners suspect that engagement on LGB issues in education is unlikely to develop positively in the near future.

\subsection{Going beyond the school gates}

In many ways, significant progress has been made in recent years, in no small part thanks to the tireless efforts of national organisations such as Stonewall (UK), Cavaria (Belgium), COC (The Netherlands) and others. European as well as national guidance, at least in Western Europe, now reflects a commitment to diversity and inclusion for all, and a significant range of tools and resources are available to schools and teachers who choose to make this a priority. All that being said, much work remains to be done to make schools across Europe more socially inclusive. Homo'poly believes that schools stand to gain much from working with pupils, not just for them, but for their wider communities in building a more safe, secure and welcoming learning environment for all. This kind of 'co-creation' - mostly with pupils, but also with parents and the wider school community - maximises the potential for schools to meet real needs, pushing the envelope on social inclusion but still staying faithful to their context and culture. This is a tried and tested approach for delivering meaningful and measurable change.

\subsection{High-level political backing opens doors}

Homo'poly's focus on 'social inclusion' aligns closely with the EU's political priorities. The European Parliament adopted a resolution on 14 February 2019 calling on the Commission to tackle the gender equality backlash targeting LGBTI people across Europe, prioritize LGBTI rights in its work in 2019-2024, and mainstream an intersectional perspective in its work, among others. Terry Reintke MEP, co-chair of the LGBTI Intergroup and shadow rapporteur for the resolution (Greens/EFA) commented that "We look forward to see the European Commission address the current backlash against gender equality - which impacts LGBTI people directly - in its current and future work. The resolution adopted with a strong majority is a clear mandate for the Commission to present a full-fledged strategy on LGBTI right with an intersectional perspective."

With a topic as sensitive and contested as LGB, having high-level political backing and financial support opens door. Homo'poly would not have achieved its results without the EU stamp of approval - the fact that these issues are supported by European leaders and programs bring people, 
projects and schools to the table. The rise of populism across the continent is a worrying trend for all of those working on the acceptance of LGB issues - both in schools and beyond. It is hoped that, by showing the significant impact of a relatively small project on the educational institutions, staff and pupils involved, further resources will continue to be dedicated to this important agenda in the future.

\section{Conclusion}

Homo'poly set out to improve awareness and acceptance of LGB in educational institutions, and - a few months before the close of the project - it has made measurable and meaningful contributions to those objectives. While there are significant results, it must be noted that much of this was due to the outstanding commitment of individual partner institutions, who worked in often difficult circumstances and who do not yet note a significant change in the overall country context - especially in Turkey and Eastern Europe. It is hoped that the learnings and materials produced by Homo'poly will be used beyond the project partners, and will prove helpful to those who champion the LGB community in Europe.

\section{Acknowledgements}

ERASMUS+ KA2 Strategic Partnership: Homo’poly. https://homopoly.eu/

\section{References}

De Witte, K., Holz, O., \& Geunis, L. (Eds.). (2018). Somewhere over the rainbow. Münster: Waxmann.

De Witte, K., Holz, O., \& Geunis, L. (2018). Coming out. A Comparative Analysis of Pupils', Teachers' and Parents' Perspectives in Eight European Countries. In K. De Witte, O. Holz \& L. Geunis (Eds.). Somewhere over the rainbow. Münster: Waxmann. pp. 11-29.

European Parliament's Intergroup on LGBT Rights (2019). European Parliament Calls on Commission to Sustain its LGBTI Strategy. Retrieved on 1 March from http://www.lgbt-ep.eu/newsstories/european-parliament-calls-on-commission-to-sustain-its-lgbti-strategy/

Geunis, L. \& Holz, O. (2018). Homo'poly - A cross-sectoral approach towards a better understanding of homosexuality. In Икономически университет (Eds.). Защита срещу дискриминацията: Правна уредба, проблеми и тенденции. Varna: Издателска къща СТЕНО. pp. 230-237.

Holz, O. \& Geunis, L. (2019). Homo'poly: helping schools, teachers and pupils build awareness and understanding of homosexuality. In V. Chiou, O. Holz, N. Oruç Ertürk \& F. Shelton (Eds.). International Insights: Equality in Education. Münster: Waxmann. (in preparation).

Holz, O. (2017). Homo'poly: Ein cross-sektoraler Ansatz zur Sensibilisierung gegenüber Homosexualität. In O. Holz, L. Vujicic, M. Duh \& M. Michielsen (Eds.). Contributions to the Development of the Contemporary Paradigm of the Institutional Childhood. Münster: LIT. pp. 375-386. 